\section{Femoral Fractures in Demented Population}

Received: January 11, 2018; Accepted: January 12, 2018; Published: January 14, 2018

\section{Editorial}

People suffering from dementia present a cluster of symptomatology which endangers further their life. Reduced balance, gait disturbance, falling from height, osteoporosis and muscle atrophy compose a series of risk factors which could provoke a femoral fracture in demented population [1], while on the other hand dementia is one of the most significant risk factors for femoral fractures [2]. This established bilateral association testifies a strongly connection between both. The incidence of femoral fractures is gradually increasing due to longer life expectancy and may lead to severe complications such as avascular necrosis, post-traumatic arthrosis, nerve injury and heterotopic ossification which are the most often complications [3]. Inter trochanteric neck fractures are most common in female of elderly age group of demented due to osteoporosis and $90 \%$ of these fractures result from only a simple fall [4]. Type 3 of the Pipkin Classification, a fracture of the femoral head, with associated fracture of the femoral neck, seem to be the more frequent type (Figure 1). As conservative methods have

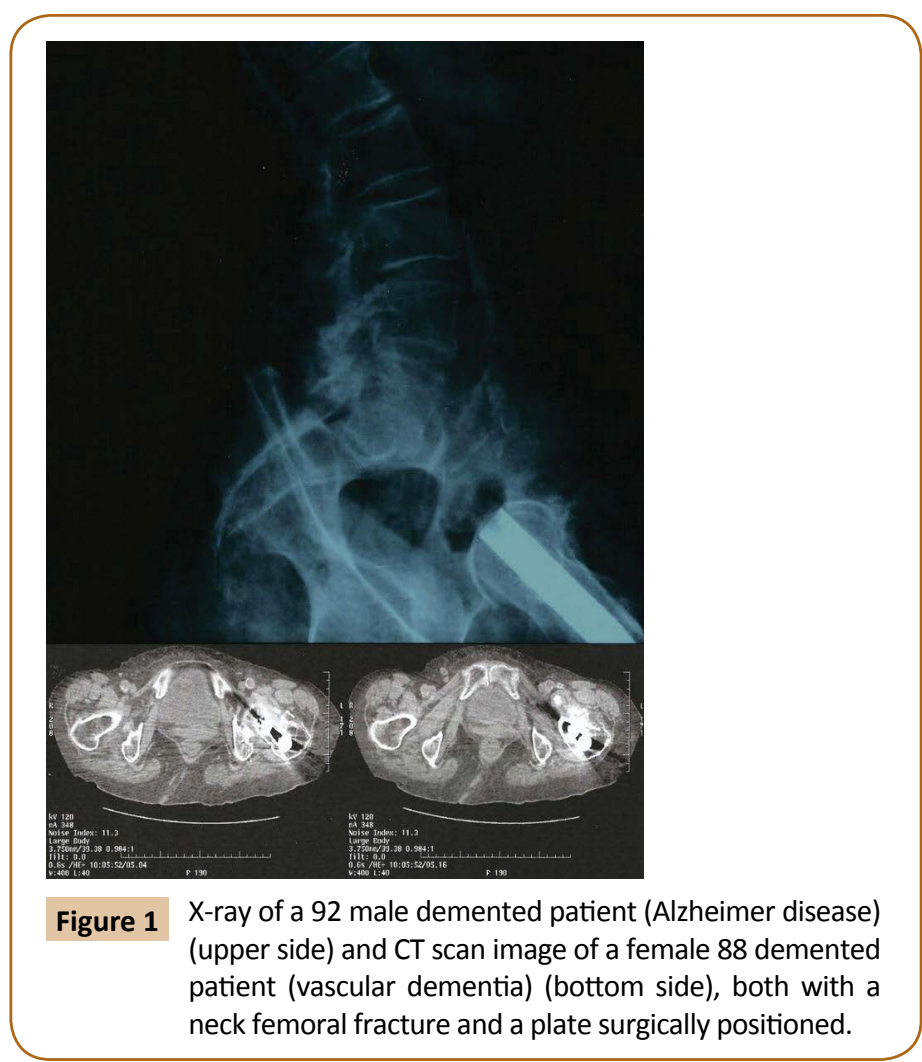

\section{Gregory Tsoucalas ${ }^{1,2 *}$ and Aliki Fiska ${ }^{2}$}
1 Hellenic Reference Centre for Alzheimer Disease and Related Dementia Syndromes, Neurologic Clinic Agios Georgios, Alykes, Volos, Greece
2 Anatomy Department, Democritus University of Thrace, Alexandroupolis, Greece

\section{Corresponding author: Gregory Tsoucalas}

\section{” gregorytsoucalas@yahoo.gr}

\begin{abstract}
Hellenic Reference Centre for Alzheimer Disease and Related Dementia Syndromes, Neurologic Clinic Agios Georgios, Alykes, Volos, Greece.
\end{abstract}

Tel: +302421078583

Citation: Tsoucalas G, Fiska A (2018)

Femoral Fractures in Demented Population. J Univer Surg. Vol.6 No.1:1

higher mortality rates, they are usually reserved for geriatric population who present high medical risk for anaesthesia and surgery. Furthermore, it has been noted that dementia patients who undergo a surgical operation could be disorganized and sometimes present a dramatic fall of conscience and cognitive level and activation of depression and anxiety syndromes. These results have been reported to be more severe in cases of end-stage dementia, where the "cognitive reserve" is further impaired. Thus, surgery by open reduction and internal fixation is not always the ideal choice of management in demented population [5]. Proximal femoral locking compression plates have been reported to have reduced mortality as well as morbidity rates and thereby reducing the risks of prolonged bed rest and associated complications. Rigid intramedullary nail fixation is also a treatment option. A multiplanar design and lateral trochanteric entry are suggested to be the key to a successful outcome with good clinical results [6]. Early surgical treatment within hours is suggested, but dementia patients re in need of a prolonged evaluation for a decision to operate to have been reached.

It is estimated that the prevalence of dementia worldwide will double every 20 years, followed eventually by a higher prevalence of skeletal traumas. Individuals who suffer from 
dementia or cognitive impairment are at substantially higher risk of sustaining a femoral fracture than those who are cognitively intact. They have up to an 8-fold higher risk of falling, usually sustaining multiple falls. "As the gerontic boom continues", with the population over 70 years continuing to be the fastest growing segment in developed countries, it is of high importance for

\section{References}

1 Tsoucalas G, Bourelia S, Markellos A, Kalogirou V, Giatsiou S, et al. (2017) Gatos Questionnaire for Early Detection of Suspicious Signs for Alzheimer Disease and Related Dementia Syndromes GQEDSS - ADRDS Q160 v 1.0. Preliminary Results. Int J Psychol Brain Sci 1: 69-85.

2 Ranstam J, Elffors L, Kanis JA (1996) A mental-functional risk score for prediction of hip fracture. Age Ageing 25: 439-442.

3 Zabrzyński J, Piechocki K, Zabrzyńska A, Szumlański A (2017) Rare case of the hip injury-posterior dislocation and femoral head fracture associated with patella fracture, case report and literature review. J Orth Trauma Surg Rel Res 12: 1-5. practitioners to understand both conditions, femoral fractures and dementia. Treatment decisions always present a huge dilemma between a conservative and a surgical intervention [7]. The authors agree with the "goals of care" model suggested by Waran and William [8], introducing a more personalized approach for every dementia patient.

4 Ibrahim S, Meleppuram JJ (2017) A retrospective analysis of surgically-treated complex proximal femur fractures with proximal femoral locking compression plate. Rev Bras Ortop 52:644-650.

5 Gregory T (2016) Anticancer Surgical Intervention in Patients with Dementia, to Operate or Not to Operate? A Huge Ethical Dilemma. J Univer Surg 4: 1-3.

6 Angadi DS, Shepherd DE, Vadivelu R, Barrett T (2014) Rigid intramedullary nail fixation of femoral fractures in adolescents: what evidence is available? J Orthop Traumatol 15:147-153.

7 Friedman SM, Menzies IB, Bukata SV, Mendelson DA, Kates SL (2010) Dementia and Hip Fractures. Geriatr Orthop Surg Rehabil 1: 52-62.

8 Waran E, William L (2016) Hip fractures and dementia: clinical decisions for the future. Oxf Med Case Rep 2: 19-21. 